\title{
Cuando el comercio internacional se encontró con el medio ambiente, entre el soft law y la prohibición a las barreras al comercio
}

Fecha de recepción: 11 de noviembre de 2016

Fecha de aceptación: 7 de noviembre de 2017

DOI: dx.doi.org/10.12804/revistas.urosario.edu.co/acdi/a.6542

\section{Juan Pablo Sarmiento Erazo*}

Resumen: la experiencia contemporánea de Colombia y América Latina muestra una tendencia a la liberalización del comercio internacional, que se ha materializado a través de acuerdos de libre comercio. En este documento se argumenta que la expansión de instrumentos internacionales ha colisionado con otros acuerdos encaminados a la protección del medio ambiente y ha visto a las normas internas acerca de esta materia como barreras al libre tráfico de bienes y servicios, lo cual ha llevado a balancear el libre comercio sobre la protección al medio ambiente, por medio de dos vías: el soft law y la ausencia de tribunales y sanciones internacionales en medio ambiente.

* Abogado de la Pontificia Universidad Javeriana; magíster y doctorado en Derecho de la Universidad de los Andes. Profesor de la Universidad del Norte; director del Grupo de Litigio de Interés Público de la Universidad del Norte. Correos electrónicos: jpsarmiento@uninorte.edu.co, jua-sarm@uniandes.edu.co. Orcid: 0000-0002-7303-3300.Este documento es resultado de la investigación financiada por la Dirección de Investigación, Desarrollo e Innovación de la Universidad del Norte, con la colaboración de Dagoberto Lavalle Navarro, abogado de la Universidad del Norte y especialista en Derecho Público de la misma universidad. Barranquilla (Atlántico).

Para citar este artículo: Sarmiento Erazo, J. P., "Cuando el comercio internacional se encontró con el medio ambiente, entre el soft law y la prohibición a las barreras al comercio", ACDI-Anuario Colombiano de Derecho Internacional , 2018, 11, pp. 187-220. DOI: dx.doi.org/10.12804/revistas.urosario.edu.co/acdi/a.6542 
Palabras clave: acuerdos de libre comercio, protección internacional al medio ambiente, soft law, hard law, barreras al comercio internacional.

\section{When International Trade Meets Environment, between Soft Law and a Ban on Trade Barriers}

Abstract: The contemporary experience of Colombia and Latin America, shows a trend towards liberalization of international trade, which has materialized through free trade agreements. This paper argues that the expansion of international instruments has collided with other agreements on environmental protection and has seen internal rules on this matter as barriers to free trade in goods and services, which has led to balance free trade on environmental protection through two channels: soft law and absence of international tribunals and penalties environment.

Keywords: Free trade agreements, international environmental protection, soft law, hard law, international trade barriers.

Quando o comércio internacional se encontrou com o meio ambiente, entre a soft law e a proibição às barreiras ao comércio

Resumo: a experiência contemporânea da Colômbia e a América Latina mostra uma tendência à liberalização do comércio internacional, que se tem materializado através de acordos de livre comércio. Neste documento se argumenta que a expansão de instrumentos internacionais tem chocado com outros acordos encaminhados à proteção ao meio ambiente e tem visto às normas internas acerca desta matéria como barreiras ao livre tráfico de bens e serviços, o que tem levado a balancear o livre comércio sobre a proteção ao meio ambiente, por meio de duas vias: a soft law e a ausência de tribunais e sanções internacionais em meio ambiente.

Palavras-chave: acordos de livre comércio, proteção internacional ao meio ambiente, soft law, hard law, barreiras ao comércio internacional. 


\section{Introducción}

A partir de la cumbre mundial sobre medio ambiente humano, celebrada en Estocolmo en 1972, se promulgó la Declaración Internacional sobre el Medio Ambiente. En palabras de Shridath Ramphal, esto fue "el principio de un cimiento sobre el cual iba a elevarse, si no un monumento a la supervivencia de la humanidad, al menos las primeras bases de construcción para mantener la Tierra como un lugar adecuado para la vida humana".

Con base en esta declaración, diversos países del mundo comenzaron a establecer políticas y dictar normas sobre la materia, como una respuesta a los graves problemas ambientales derivados del acelerado crecimiento económico registrado en los países industrializados durante la etapa de posguerra. Fue así como en el escenario internacional, y en el marco de la libre apreciación de las obligaciones convenidas en la mencionada declaración, ${ }^{1}$ el tema ambiental empezó a tomar mayor trascendencia, conduciendo luego a la celebración de otros instrumentos internacionales sobre medio ambiente, a saber: la Declaración de Río sobre el Medio Ambiente y el Desarrollo, la Convención Marco de

1 Concretamente, en Colombia, como consecuencia de la Convención de Estocolmo, se procuró el fortalecimiento institucional del Instituto Nacional de los Recursos Naturales Renovables y del Ambiente (Inderena). Igualmente, el Congreso colombiano procuró el desarrollo normativo en garantía del medio ambiente, así se expidió la Ley 23 de 1973, que concibió al medio ambiente como patrimonio común de los colombianos y autorizó al ejecutivo para la expedición de un código de recursos naturales, que luego sería compendiado en el Decreto-Ley 2811 de 1974. Con la expedición del Código de Recursos Naturales se armonizó la legislación dispersa existente en el momento y se imputó la gestión ambiental en cabeza del ejecutivo. Este estatuto, todavía vigente, establece que el ambiente es patrimonio común y que el manejo de los recursos naturales es de utilidad pública e interés social, también regula lo relacionado con la defensa del medio ambiente y de los recursos naturales renovables, y establece las condiciones de uso y aprovechamiento de tales recursos, etc. Empero, antes de la década de los noventa el derecho ambiental colombiano todavía era muy incipiente, fue con la Constitución Política de 1991 que se logró incorporar la dimensión ambiental en el ideario político. Gracias a la Constitución de 1991, el tema ambiental alcanza su máxima jerarquía jurídica. En esta se consagraron, aproximadamente, 50 disposiciones que se relacionan directa o indirectamente con el tema ambiental. En últimas, ha sido un hecho reiterado por la Corte Constitucional que en Colombia, en materia ambiental, La Constitución Política hace gala de uno de los sistemas más completos que para la protección del medio ambiente han producido los Estados constitucionales modernos, así, es también conocida como 'Constitución Verde' o 'Constitución Ecológica' (Sánchez, 2002, p. 92). 
las Naciones Unidas sobre el Cambio Climático, el Convenio sobre la Diversidad Biológica y el Protocolo de Kioto sobre el cambio climático, entre muchos otros. ${ }^{2}$

Frente a la preocupación global por el medio ambiente, paralela a la proliferación de instrumentos jurídicos nacionales e internacionales, la atención del asunto ambiental comenzó a colisionar paulatinamente con el comercio internacional, y a significar, de alguna manera, una barrera al libre tráfico de bienes y servicios. Algunos autores advirtieron la necesaria colisión entre el medio ambiente y la liberalización del comercio internacional, debido a que, en primer lugar, por la diferencia en costos de control de contaminantes, las empresas "sucias" se establecerán en el país con menor costo, convirtiéndolo en un "paraíso de contaminadores". Segundo, las diferencias en costos de control ambiental entre países constituyen una ventaja desleal, por lo que deberían establecerse impuestos compensatorios o igualarse las normas ambientales.

En la actualidad, se encuentran en vigor más de 250 acuerdos multilaterales sobre el medio ambiente (Amuma) relativos a diversas cuestiones ambientales, de los cuales aproximadamente 20 desarrollan disposiciones que pueden afectar al comercio (OMC, 2016). En este sentido, bajo las directrices derivadas del concepto "desarrollo sostenible", los acuerdos comerciales o tratados de libre comercio han incluido aspectos normativos para la protección del medio ambiente y, a la vez, han promovido el libre comercio entre países, advirtiendo que los primeros no pueden suponer una restricción al comercio internacional.

\footnotetext{
2 Otros convenios internacionales suscritos para la protección del medio ambiente son: Convención sobre el Comercio Internacional de Especies Amenazadas de Fauna y Flora Silvestres; Protocolo de Cartagena sobre Seguridad de la Biotecnología; Convenio Internacional para la Protección de las Obtenciones Vegetales; Convenio de Cartagena sobre la Protección y el Desarrollo del Medio Marino en la Región del Caribe; Protocolo relativo a la Cooperación para Combatir los Derrames de Hidrocarburos en la Región del Gran Caribe; Convenio de Viena para la Protección de la Capa de Ozono; Protocolo de Montreal relativo a las Sustancias que Agotan la Capa de Ozono; Convenio de Basilea sobre el Movimiento Transfronterizo de Desechos Peligrosos; Convenio Marco del Cambio Climático; Convenio Internacional de las Maderas Tropicales; Convenio de Rotterdam sobre el Procedimiento de Consentimiento Fundamentado Previo Aplicable a Ciertos Plaguicidas y Productos Químicos en el Comercio Internacional; Convenio de Estocolmo sobre los Contaminantes Orgánicos Persistentes (POPS) (Ministerio de Ambiente, Vivienda y Desarrollo Territorial, 2011).
} 
Esto último lleva a cuestionar el peso que pueden tener los instrumentos jurídicos internacionales sobre el medio ambiente, frente a aquellos que promueven la liberalización del comercio. Lo antedicho podría conducir a un bajo nivel de aplicación, particularmente en regiones del sur global, como América Latina, que parecerían relativizar la aplicación de normas ambientales en aras de obtener un rápido desarrollo económico. En el derecho internacional, el panorama tampoco parece ser diferente, pues se puede constatar la inexistencia de mecanismos jurisdiccionales idóneos para exigir el cumplimiento de los compromisos ambientales asumidos, situación aunada a la dependencia de los instrumentos internacionales al desarrollo del derecho interno y su eficacia. Se trata de un derecho esencialmente político y programático. Incluso, algunos autores señalan que la mayoría de composiciones normativas sobre medio ambiente en el marco del derecho internacional, configuran normas soft law o de "derecho blando", circunstancia acompañada por un déficit de hard law y un evidente debilitamiento normativo.

Distanciándonos un poco de la eficacia jurídica, ${ }^{3}$ el presente texto argumenta la debilidad prescriptiva de las normas relativas a la protección del medio ambiente y el desarrollo sostenible, y, en últimas, la inidoneidad jurídica para el cumplimiento de obligaciones y compromisos exigibles en el escenario internacional. Así las cosas, se plantea la priorización jurídica de los acuerdos que liberalizan el comercio internacional sobre las convenciones de protección ambiental, considerando la mayor rigurosidad normativa en el cumplimiento de compromisos internacionales frente a un "ablandamiento" que progresivamente ha circunscrito el tema ambiental. En este documento, se estudia concretamente la situación de Colombia y las inclusiones relativas al medio ambiente de los tratados de libre comercio vigentes. Previo a tal análisis, se hace una observación general del peso que ha perdido el tema ambiental en el escenario internacional, y se indican las tensiones entre tal asunto con lo comercial. Lo anterior se desarrollará a partir de las categorías de hard law y soft law, como

3 A primeras, la expresión 'eficacia' a nivel jurídico ha suscitado múltiples construcciones teóricas. Siguiendo a varios tratadistas, la eficacia alude a un tema de obedecimiento y aplicación de las normas jurídicas por parte de sus destinatarios y operarios. En todo caso, teniendo presente su equivocidad, la eficacia, para efectos del presente texto, obedece a la consecución de sus fines políticos y sociales bajo una concepción instrumental del derecho (García, 2006). 
herramientas analíticas que estratégicamente le han restado peso al derecho internacional del medio ambiente.

\section{E1 predominio del soft law y el vaciamiento del contenido normativo del derecho internacional ambiental}

Las categorías soft law o hard law no ostentan una definición precisa, mucho menos inequívoca. ${ }^{4}$ Tales expresiones guardan origen en marcos analíticos del derecho internacional y son empleadas por la doctrina para explicar diferentes realidades. No obstante, aluden a la dicotomía de disposiciones normativas que, por un lado, se erigen para vincular y coaccionar en determinado grado el comportamiento de los Estados — hard law-; y, por otro, para producir efectos jurídicos distintos, sin implicar necesariamente la imposición de consecuencias normativas o mayor grado de obligatoriedad, guardando al menos cierta relevancia jurídica — soft law-.

Tradicionalmente, las diferencias entre soft law y hard law se hacen con base en el sistema de fuentes del derecho internacional, siendo los primeros aquellos actos incardinados como recomendaciones, resoluciones, instrucciones, planes, circulares, normas técnicas, cartas de servicios, códigos de conducta o de buen gobierno, entre otros. No obstante, más allá de las denominaciones, es el carácter vinculante, entre otros aspectos, el que servirá como rasgo distintivo dentro de tales categorías. Acorde con Abbott y Snidal, las distinciones entre el hard law y el soft law operan principalmente bajo tres dimensiones: la precisión de las normas (bien sea mediante la adjudicación o emisión de reglamentos detallados), la gradación de la obligación o grado de vinculatoriedad, y la delegación normativa a un tercero para su interpretación y aplicación (aspecto en el cual se in-

\footnotetext{
4 Aunque se reconoce que el término soft law fue introducido al lenguaje del derecho internacional por Lord McNair, lo cierto es que este acunó el término para distinguir entre proposiciones de lege lata y de lege ferenda, y no para distinguir un fenómeno complejo que supone la existencia de variaciones normativas que van desde lo no vinculante hasta lo vinculante, del 'no derecho' al derecho, de lo soft a lo hard. Inicialmente con la expresión soft law se trataba de describir enunciados formulados como principios abstractos, con el transcurrir del tiempo el profesor Prosper Weil expuso los riesgos del derecho internacional ocasionado por una excesiva variación normativa. Hoy por hoy, las expresiones soft law y hard law han adquirido mucha relevancia a nivel académico, no obstante, no deja de ser un término todavía ambiguo y fuertemente criticado (Del Toro, 2006, p. 518).
} 
troduce también la participación de actores no estatales como autoridad delegada). Bajo este orden de ideas, el hard law se distinguirá por ser un instrumento fuertemente institucionalizado, contrario al soft law que pasa a ser una categoría residual, cuyo punto de partida es el debilitamiento en una o más de las dimensiones antes descritas.

Así las cosas, se hace referencia al soft law en la medida que los acuerdos o normas jurídicas no sean formalmente vinculantes - gradación de obligación -; su contenido sea vago u otorgue discrecionalidad a las partes para su cumplimiento y/o aplicación; aquí, pese a tratarse de instrumentos vinculantes, en realidad no imponen obligación exigible —precisión-; o no existe institución/autoridad alguna para su supervisión, interpretación e implementación — delegación — . Respecto esta última dimensión, sobra decir que, al no existir tercera parte que sirva de "punto focal", se abre espacio a las partes para justificar discursivamente sus actos con mayor facilidad en términos legales, y, en consecuencia, prestar menor atención a su cumplimiento.

Para autores como Valencia, el soft law se puede entender como una declaración entre la ética (es un deber ser moral) y la política legislativa. Este autor propone llamar al soft law como soft rules, debido a que consiste en normas o reglas éticas de política legislativa. Por esto, la finalidad del soft law es prefigurar el derecho y, sobre todo, preparar a la comunidad internacional, usualmente fracturada, para que las conductas descritas en él lleguen a convertirse, más temprano que tarde, en auténtico derecho internacional bajo las normas consuetudinarias o convencionales.

Cabe decir que doctrinantes como Chinkin refuerzan la categoría del soft law desde otros presupuestos: se trata de normas ajenas a cualquier teoría de la responsabilidad; o que se basan exclusivamente en la adhesión voluntaria por parte de los Estados, o no existen mecanismos para su exigibilidad; y/o, por último, que estén dirigidas a actores no estatales. En cualquier caso, el mayor déficit en una o varias de las dimensiones anotadas permite reconocer puntos intermedios entre el soft law y el hard law, existiendo reglas jurídicas legal soft law, que bien decantan la balanza hacia el law, y no jurídicas non-legal soft law, que lo hacen hacia el soft, según chicharro.

Por supuesto, los defectos sobre las dimensiones anotadas tampoco deben considerarse como una facultad para la inobservancia total de las normas o acuerdos jurídicos, ya que plasman la voluntad política de los actores, que al menos cuentan con cierta relevancia jurídica. En principio, la carencia de obligatoriedad desde el punto de vista jurídico de las reglas del soft law supone un grave impedimento a la hora de hacer cumplir 
los compromisos adquiridos en esta materia; sin embargo, esta clase de instrumentos también permite proyectar principios y criterios jurídicos, que, aun sin ser vinculantes u obligatorios, marcan derroteros en la futura regulación jurídica, tanto a nivel internacional como a nivel interno.

Por otro lado, el empleo del hard law se muestra muy útil en ciertos aspectos relativos a la conformación de acuerdos internacionales, así como la ordenación de las relaciones entre actores internacionales, y el reforzamiento de la credibilidad en los compromisos asumidos. Con todo, esta última categoría también implica ciertos costes teniendo en cuenta las restricciones que impone en el comportamiento de los actores, llegando a afectar incluso su soberanía. Dicho esto, ambas categorías presentan distintas ventajas en relación con la otra, razón por la que se exige su implementación simultánea bajo lo que se considera una estrategia de gobernanza a nivel internacional.

La dualidad entre soft law y hard law, pese a sus distinciones, no parecería marcar fronteras diferenciadoras entre sí. En realidad, son complementarios si se entienden como la persecución de objetivos políticos. El soft law puede ser importante para la obtención de resultados adicionales e integradores, si se logra que los Estados se obliguen a unos determinados mínimos, mientras que los "máximos" pueden quedar plasmados en textos con cláusulas no forzosas, que apunten la ruta por seguir pero de manera no imperativa. Además, con el tiempo puede que el contenido de los instrumentos del soft law logre los adeptos suficientes para cambiar su naturaleza y convertirse en hard law.

Empero, bajo este mismo orden, parte de las tensiones que se enunciaron surgen al considerar que la eficacia del soft law depende en alguna medida del éxito del hard law. Sin embargo, la ambivalencia del soft law también puede ser empleada para dirimir tensiones entre los procesos de integración económica y la conservación ambiental. Con todo, su desarrollo representa un cierto refuerzo del "símbolo legal", en especial en eventos que representan una mayor composición normativa. Así las cosas, el uso excesivo del soft law tiene repercusiones a largo plazo; en última instancia, puede debilitar todo el sistema legislativo internacional.

En efecto, esta última situación, donde las composiciones normativas son soft law, pareciera ser un hecho que prevalece a nivel internacional en aquellas medidas de protección al medio ambiente. En términos generales, los Estados se han mostrado reacios a asumir compromisos jurídicamente vinculantes en la materia (Chicharro, 2013, p. 23; Valencia, 2003, p. 495), por lo que buena parte de los instrumentos internacionales no cuentan 
con mecanismos de mayor capacidad de coacción, habiendo un déficit de hard law y una carencia de medios para obligar al cumplimiento de los compromisos suscritos, lo que se traduce en un debilitamiento normativo. Incluso, instrumentos que en principio son de naturaleza vinculante, tales como la Declaración de Río sobre el Medio Ambiente y el Desarrollo, la Declaración sobre los Bosques y el Programa 21, los cuales son acuerdos interestatales no normativos, carecen de vinculación jurídica y, por lo tanto, cuentan con contenidos normativos debilitados que difícilmente permiten considerar la existencia de un grado significativo de vinculación de los Estados, siendo en realidad normas soft law, o, en palabras de Chicharro, un caso de soft law material.

Un ejemplo de lo afirmado es la Convención Marco de las Naciones Unidas sobre el Cambio Climático (CMNUCC), y, más concretamente, el Protocolo de Kioto, que son instrumentos erigidos para el compromiso de los países de reducir las emisiones de gases de efecto invernadero. A primera vista, este último correspondería con una estructuración normativa vinculante propia del hard law, con estructuras importantes como un sistema de incentivos para los Estados, encaminado al cumplimiento efectivo de los objetivos trazados para prevención de eventuales afectaciones por cambio climático. Sin embargo, observado el comportamiento de los Estados vinculados, el proceso de implementación y su contenido, se hace notable un debilitamiento normativo importante, sin mayores formas de control sobre los Estados.

El Protocolo de Kioto entró en vigor el 16 de febrero de 2005, después de que fuese ratificado por 55 Estados, que sumaban el 55\% de las emisiones de efecto invernadero a la atmósfera, y tras haber acordado unas instrucciones sobre la manera de instrumentalizarlo. A la fecha, son 193 las partes (192 Estados y 1 organización regional de integración económica) que comprende el acuerdo correspondiente a un 63,7\% del porcentaje total de emisiones de gases de invernadero por parte de quienes integran el mencionado protocolo (Naciones Unidas, 2016c), de manera que las ausencias de dicho instrumento todavía son significativas. Esto considerando que el casi $40 \%$ de los países responsables de emisiones a la atmósfera se encuentra excluido, en el que se resalta el rechazo de Estados Unidos por ratificar el acuerdo, uno de los países más contaminantes 
junto con la República Popular de China, ${ }^{5}$ quien también había expresado reservas para su adopción. ${ }^{6}$

Por otro lado, el Protocolo de Kioto cuenta esencialmente con mecanismos flexibles para su implementación. En virtud de este, los países tienen que alcanzar sus metas principalmente a través de medidas nacionales (Naciones Unidas, 2016b), y, suplementariamente, cuenta con herramientas y mecanismos diseñados por el tratado. Estos últimos operan también para su cumplimiento, y son estructuras que tienen propiedades de soft law, teniendo en cuenta los altos márgenes de discrecionalidad que estos ofrecen al tratarse en esencia de un sistema de incentivos sin sanciones económicas. Así las cosas, pese a contar con instrumentos para el monitoreo del cumplimiento del tratado, como el Comité de Cumplimiento (Compliance Committee), el Protocolo de Kioto se apoya en el mercado para incentivar la reducción de emisiones por medio de varios mecanismos (Naciones Unidas, 2016).

Tales incentivos son: 1) el "comercio de los derechos de emisión" (lo que se conoce también como "el mercado del carbono") se funda en el artículo 17 del protocolo, y permite que los países negocien con sus metas de emisión de carbón, por medio de la contabilización de las metas de reducción de emisiones en unidades ("unidades de la cantidad atribuida", UCA, que pueden ser transables bajo el supuesto de que haya un exceso positivo sobre los objetivos alcanzados); 2) el "mecanismo para un desarrollo limpio" MDL, definido en el artículo 12, autoriza la ejecución de proyectos de reducción de las emisiones en países en desarrollo, a fin de conseguir créditos "por reducciones certificadas de las emisiones" (RCE

5 Acorde con la ONU, Estados Unidos y China representan al menos el $40 \%$ de las emisiones globales de gases contaminantes de la atmósfera. El entonces secretario de Estado estadounidense, John Kerry señaló ante este informe, que se esperaba la ratificación del pacto por parte de Estados Unidos en el transcurso del año 2016. (Naciones Unidas. 2016b)

6 Por medio de comunicados oficiales, el gobierno de la República Popular China informó al Secretario General sobre la implementación transicional del Protocolo de Kioto de la Convención Marco de las Naciones Unidas sobre el Cambio Climático (CMNUCC). Así, para el año 2003 el protocolo no era aplicado provisionalmente a la Región Administrativa Especial de Hong Kong y a la Región Administrativa Especial de Macao. Fue hasta el 14 de enero de 2008 que se hizo notificación oficial de la Ley Básica de la Región Administrativa Especial de Macao de la República Popular China, por medio de la cual se decidía aplicar el Protocolo de Kioto en la Región Macao. Antes, el 8 de abril de 2003, se había hecho comunicación de la aplicación del acuerdo en Hong Kong. 
o CER; 3) la "aplicación conjunta", establecida en el artículo 6 $6^{\circ}$, habilita la obtención de UCA mediante la participación en proyectos de reducción o eliminación de las emisiones de otra parte vinculada. Y adicional a los descritos, se cuenta con un "fondo de adaptación”, diseñado para ayudar a los países a adaptarse a los efectos adversos del cambio climático, y financiado con el $2 \%$ de los CER emitidos por proyectos de MDL y otras procedencias.

Como se constata, se trata de un mecanismo de incentivo, que carece de sanciones económicas. Las medidas de coerción se materializan en la suspensión del acceso al mercado de emisiones, o bien al establecimiento de tasas de restauración sobre las metas del período siguiente al incumplido. ${ }^{7}$ Esto pone de manifiesto la flexibilidad del instrumento jurídico señalado, y reafirma la tesis sobre la eficacia relativa de sus normas. A grandes rasgos la aplicación de medidas flexibles no ha mostrado tener hasta ahora mayores efectos. Un ejemplo muy claro de lo sostenido es el abandono del acuerdo por parte de Canadá, que simplemente no tuvo consecuencia alguna frente a su probable incumplimiento. ${ }^{8}$ En otras palabras,

$\mathrm{Al}$ respecto, el Acuerdo de Bonn (2001) sobre el Protocolo de Kioto, considerado un hito político en las lentas negociaciones internacionales. Los ministros de unos 180 países llegaron a un acuerdo global que incluía normas y procedimientos sobre diversos asuntos de los países en desarrollo (fondos, traspaso de tecnología, capacitación, adaptación a los impactos del cambio climático), los mecanismos de Kioto (comercio de emisiones, aplicación conjunta y mecanismo de desarrollo limpio), sumideros y cumplimiento. En su conjunto, el acuerdo creó la arquitectura fundamental básica para que los países ratificasen y pusiesen en práctica el protocolo, y para que negociasen futuros recortes de emisiones más estrictos. Entre los puntos principales del Acuerdo de Bonn se incluyen: i) dar un tratamiento preferente a las energías renovables limpias bajo el mecanismo de desarrollo limpio; ii) pedir a los países industrializados que frenen el fomento de la energía nuclear en los países en desarrollo. De hecho, los gobiernos han dicho no a la energía nuclear como modo de frenar la contaminación por carbono; iii) normas factibles para el comercio de emisiones; iv) un régimen de cumplimiento que incluya consecuencias no opcionales, de obligado cumplimiento para aquellos países que no alcancen sus compromisos. Posteriormente, los asuntos que quedaron pendientes en Bonn sin resolver fueron concluidos en la Conferencia de Marrakech en octubre de 2001 (World Wide Fund for Nature, 2016).

8 Cabe decir que, de conformidad con el artículo 27 (1) del Protocolo de Kioto de la CMNUCC, el gobierno de Canadá notificó al Secretario General de las Naciones Unidas su decisión de retirarse del protocolo, acción efectiva desde el 15 de diciembre de 2012. Ténganse las siguientes consideraciones: "If Canada were found by the enforcement branch to be in non-compliance with the reporting requirements [...], the enforcement branch could require Canada to submit a plan [...] [However] the focus of such a plan would be on remedies for the non-compliance. Thus, it is not clear, given the purpose of such a plan, whether Canada, which no longer has substantive commitments under the Kyoto 
lo determinante para definir el nivel vinculante — hard o soft law — no es el título que adquiera el documento, sino la intención de las partes para crear relaciones jurídicamente vinculantes.

El proceso de implementación del Protocolo de Kioto por algunos sectores ha sido considerado un fracaso de la comunidad internacional para la reducción de la contaminación por carbono. ${ }^{9}$ Exceptuando algunos logros, las emisiones de gases de efecto invernadero a la atmósfera han aumentado durante el período de vigencia de los compromisos adquiridos en Kioto, habiendo experimentado un descenso únicamente durante la crisis económica de 2008 y 2009. Las decisiones internacionales se han movido regresivamente, cada vez más desatendiendo los procesos de mitigación, procurando ahora la adaptación de mecanismos para la compensación por pérdidas y daños, con menor atención a la búsqueda de soluciones efectivas sobre las causas de la crisis climática.

Las renegociaciones del acuerdo tampoco han logrado mayores compromisos. La cumbre de Bali de 2007, diseñada para construir un acuerdo que sustituyera el Protocolo de Kioto a partir de 2013, se convirtió en una declaración política de intenciones, sin compromisos jurídicamente vinculantes, en la que no se establecieron objetivos claros para la reducción de gases de efecto invernadero. Posteriormente, en Cancún (México), año 2010, los Estados vinculados, pese a lograr una demarcación de objetivos concretos - la reducción de los gases de efecto invernadero de entre un $25 \%$ y un $40 \%$ para 2020 - tampoco se obtuvo un acuerdo vinculante y aceptado por todos los participantes en materia de reduc-

Protocol, could be required to submit it, or how submitting such a plan would be useful to Canada. [...] [Also] if Canada were found to be in non-compliance with the one or more of the eligibility requirements under Article 6,12 and 17 of the Kyoto Protocol, under section XV, paragraph 4, of the annex to decision 27/CMP.1, the enforcement branch could suspend Canada from participation in the mechanisms. However, Canada is already disconnected from the International Transaction Log and has not been participating in the Kyoto market-based mechanisms since it ceased to be a Party to the Kyoto Protocol" (Compliance Committee, 2014).

9 El documento citado contiene los resultados y valoraciones críticas hechas sobre los acuerdos de la $18^{\mathrm{a}}$ Conferencia de las Partes de la Convención Marco de las Naciones Unidas sobre el Cambio Climático (COP 18); y la $8^{a}$ Reunión de las Partes del Protocolo de Kyoto (MOP 8) realizadas en Doha (Qatar), del 26 de noviembre al 8 de diciembre de 2012. En dicha conferencia participaron cerca de 9000 personas, incluyendo 4356 oficiales de gobierno, 3956 representantes de órganos de las Naciones Unidas, agencias, organizaciones de sociedad civil, y 683 representantes de medios de comunicación. 
ción de emisiones, de ayudas económicas y tecnológicas efectivas para la adaptación al cambio climático de los países más vulnerables, y confirmó un elevado grado de indiferencia de los Estados desarrollados al diferir sus compromisos con las soluciones más adecuadas a los problemas que ellos, en gran medida, han contribuido a generar. Igualmente, el reciente acuerdo celebrado tampoco expone mayores compromisos, a largo plazo se procura limitar el aumento de la temperatura a $1,5^{\circ} \mathrm{C}$ sobre los niveles preindustriales, para lo cual se proponen los países partes "lograr que las emisiones mundiales de gases de efecto invernadero alcancen su punto máximo lo antes posible, teniendo presente que los países en desarrollo tardarán más en lograrlo, y a partir de ese momento reducir rápidamente las emisiones de gases de efecto invernadero".

En efecto, este acuerdo también se compone de normas no vinculantes y otorga a los Estados una enorme flexibilidad en el cumplimiento de sus normas. En efecto, el Acuerdo de París establece la obligación de reducir las emisiones de gases invernadero de manera voluntaria, a través de las llamadas "contribuciones determinadas a nivel nacional" cada cinco años, pero no señaló nada sobre contribuciones obligatorias de reducción de emisiones con metas cuantificadas. Simplemente, se planteó la necesidad de lograr mantener el aumento de temperatura en los $2^{\circ} \mathrm{C}$ respecto a los niveles preindustriales, según lo establece el artículo 2.1, inciso a); así como la necesidad de que los países suscritos alcancen su "punto máximo lo antes posible" —artículo 4.1-. De esta forma, cada país debe reducir progresivamente sus emisiones, de manera acumulada, con el fin de lograr las metas comunes del Acuerdo de París a largo plazo y de forma voluntaria, cada cinco años, pero nada se estableció sobre el grado de progresividad que debe alcanzarse cada quinquenio. El Acuerdo de París, además, invita a los países suscritos a adoptar medidas para conservar y aumentar los sumideros y reservorios de gases de efecto invernadero; "alienta" a las partes a que adopten medidas para aplicar y apoyar incentivos para reducir las emisiones debidas a la deforestación y la degradación de los bosques; y para estimular la función de la conservación, la gestión sostenible de los bosques. Finalmente, como elemento determinante, se constata que el acuerdo establece un mecanismo no contencioso para los casos de incumplimiento, que es resuelto por un comité compuesto por expertos facilitadores para la aplicación y promoción en el acatamiento de las disposiciones del tratado — artículo 15- .

Como se constata, actualmente no existen mecanismos para la coerción o sanción de los actos de los Estados, por lo menos en lo que respecta 
al medio ambiente. Teniendo en cuenta la formulación de los contenidos normativos, la mayoría de construcciones de estos convenios se reducen a ser disposiciones soft law, y devienen ineficaces, en la medida en que permiten evadir la asunción de compromisos y nuevas responsabilidades que produzcan cambios significativos en la gestión del medio ambiente global.

Sin adentrarnos en la discusión sobre la eficacia de los instrumentos transnacionales sobre el medio ambiente, se evidencia además que los países latinoamericanos alcanzan objetivos ambientales limitados, debido a que, en algunos casos, cuentan con aparatos normativos flexibles, superficiales o insuficientes, o porque se tienen insumos institucionales y administrativos débiles y frágiles, en términos de transparencia, capacidad funcional e instalada y recursos fiscales. En efecto, lo señalado sobre los ordenamientos internos ha sido previamente anotado por la comunidad internacional con ocasión de la Cumbre de Johannesburgo sobre Desarrollo Sostenible de 2002, al discutirse acerca de las razones de la ineficacia de las legislaciones internas, entre las cuales se añade a las mencionadas la aplicación de concepciones equivocadas sobre "desarrollo sostenible". ${ }^{10}$ Esto se constata por demás en el hecho de que no se ha superado a la fecha ninguno de los problemas de emisiones de gas de invernadero, incluso a pesar de los impulsos que ha logrado el apoyo de la comunidad internacional; llama la atención las formas cómo, desde lo jurídico, la liberalización del comercio ha alterado el concepto de desarrollo sostenible.

En efecto, es notable que los acuerdos comerciales celebrados entre Estados juegan un papel importante para la promoción del desarrollo sostenible, que constituyen un elemento de integración que va más allá de la simple reducción arancelaria y que comprende mayores disposiciones

\footnotetext{
10 Acorde con Raúl Brañes Ballesteros en la preparación de la Cumbre de Johannesburgo sobre Desarrollo Sostenible (2002): "Entre los factores que hacen ineficiente la legislación ambiental se encuentran, en mi opinión, tanto su falta de desarrollo como el enfoque equivocado que asume para el tratamiento de los asuntos ambientales cuando concurren todos o algunos de los siguientes elementos: 1) la falta de presencia de la idea del desarrollo sostenible en el sistema jurídico en general y, especialmente, en la legislación económica; 2) la carencia de instrumentos apropiados para su aplicación, en particular de aquellos de naturaleza preventiva; 3 ) la falta de consideración de las cuestiones sociales y naturales involucradas en los asuntos ambientales; y 4) su heterogeneidad no sólo material sino también estructural. Y entre los factores que hacen ineficaz la legislación ambiental se encuentran: 1) la insuficiente valoración social de la legislación ambiental por sus destinatarios e incluso su desconocimiento; y 2) las deficiencias que presentan las instituciones encargadas de aplicarla administrativa y judicialmente" (Rey, 2008, p. 15).
} 
relativas al medio ambiente. Dentro de estos, se entiende que la liberalización del comercio es una herramienta más para la promoción del desarrollo sostenible y la protección al medio ambiente. De acuerdo con las orientaciones políticas de la Organización Mundial del Comercio (en adelante OMC), la apertura del comercio es un medio importante para la reducción de la pobreza, el intercambio de tecnologías verdes y la protección al medio ambiente. ${ }^{11}$ Empero, casi a manera de antítesis y paralelo a dichas orientaciones, se reconoce también por parte de la misma OMC eventos de degradación ambiental vinculados con el comercio internacional, conocidos bajo cinco casos-prototipo de un determinado problema ambiental: la agricultura intensiva, que representa problemas ambientales cuyos efectos son principalmente locales; la lluvia ácida, reconocida como un problema de contaminación transnacional cuyos efectos están limitados a ciertas regiones más o menos fronterizas; la deforestación, que tiene elementos de falta de mercados y vínculos con otros problemas ambientales, como el calentamiento global; la sobreexplotación de recursos pesqueros, relacionada con el agotamiento de recursos renovables y de la cadena alimenticia global.

La OMC comprende también advertencias sobre los problemas asociados a la contaminación y degradación general de recursos naturales, vinculadas a la ejecución de ciertas actividades comerciales, en el texto "Lucha contra la contaminación industrial y el comercio internacional". ${ }^{12}$

11 Bajo esta línea discursiva, se considera que la liberalización comercial estimula el crecimiento y los niveles de ingresos, por lo que conduce a una utilización más eficiente de los recursos, apoyando así la conservación de los recursos y la sostenibilidad; así mismo, se afirma el aumento de tamaño de los mercados para los productores de bienes acabados y los proveedores de componentes, incrementando así los beneficios de la innovación para los que participan en las redes de producción relacionadas con bienes verdes; y, finalmente, el acceso a una gran variedad de bienes y servicios importados en los que intervienen tecnologías respetuosas con el medio ambiente a un precio más bajo. Al respecto, ver: OMC, Aprovechamiento del comercio para un desarrollo sostenible y una economía verde, 2011. En contraposición, Chichilnisky afirma que el comercio internacional si bien iguala los precios de los bienes y de los factores a nivel mundial, no mejora la asignación de los recursos. De igual forma, en el conjunto de la economía mundial los recursos están infravalorados, hay exceso de producción en un país y exceso de consumo en el otro, lo que en realidad significa que el comportamiento de los mercados es mucho más complejo que el panorama antes descrito (1994, p. 851).

12 En el citado documento, la OMC hace un breve recorrido sobre la creación del Grupo de las Medidas Ambientales y el Comercio Internacional (Grupo MACI), que se concibió en 1971, pero solo se reunió en 1991, previamente a la Conferencia de las Naciones Unidas sobre el Medio Ambiente y el Desarrollo (CNUMAD). Con todo, señala el texto citado, es en 
Todo esto es muestra de las contradicciones internas de un concepto base de las relaciones comerciales actuales, que guarda suma relevancia para la gestión del medio ambiente y la composición del concepto de desarrollo sostenible. ${ }^{13}$ En últimas, como se verá a continuación, tal concepto integrado en el interior de los tratados de libre comercio jurídicamente significará - al menos en Colombia- la priorización de los intereses comerciales sobre la protección del medio ambiente. Así las cosas, a continuación se demostrará, atendiendo al caso colombiano, la debilidad de las previsiones normativas ambientales persistente en los TLC, aun en los acuerdos que más han profundizado sobre el asunto ambiental, los cuales son los suscritos con Canadá, Chile, la Unión Europea y Estados Unidos. No obstante, previamente se introduce muy brevemente el contexto colombiano, que actualmente es escenario de un gran número de conflictos ambientales, resultantes principalmente de las actividades extractivas. Bajo dichos supuestos, se precisará la respuesta normativa de los acuerdos comerciales frente a la disyuntiva existente entre la liberalización del comercio y la protección del medio ambiente.

la Ronda Uruguay (1986 a 1994) donde se abordaron las cuestiones ambientales relacionadas con el comercio y se introdujeron modificaciones en el Acuerdo OTC, se incluyeron elementos ambientales en el Acuerdo General sobre el Comercio de Servicios (AGCS), en los acuerdos sobre la Agricultura, Medidas Sanitarias y Fitosanitarias, Subvenciones y Medidas Compensatorias, y en los Aspectos de los Derechos de Propiedad Intelectual relacionados con el Comercio (ADPIC). Otro hito que se resalta es la Reunión Ministerial del GATT de 1982, que llevó a la creación en 1989 del Grupo de Trabajo sobre la Exportación de mercancías cuya venta está prohibida en el país de origen y otras sustancias peligrosas, donde se examinaron cuáles eran las medidas necesarias para someter a control la exportación de productos, cuya venta está prohibida en el país de origen por los riesgos a la salud y la vida de las personas y de los animales o a la preservación de los vegetales, o al medio ambiente.

13 En efecto, a partir de las décadas de los ochenta y noventa, especialmente a raíz de la Comisión Brundtland y luego de la Cumbre de Río de 1992, los países incluyeron dentro de los temas de la agenda mundial la relación entre comercio y medio ambiente. Fue precisamente en el Informe Brundtland donde la ex primera ministra de noruega Gro Harlem Bruntland en 1987 empleó por primera vez el término "desarrollo sostenible" como una expresión político-jurídica ambiental, definida como "el desarrollo que satisface las necesidades y aspiraciones del presente sin comprometer la habilidad para satisfacer aquellas del futuro" (World Commission on Environment and Development, United Nations, 1987, p. 41). 


\section{Colombia, conflictos ambientales y la respuesta de los TLC: entre el soft law y la inclusión de compromisos blandos en materia ambiental}

De acuerdo con el sistema de información sobre biodiversidad de Colombia, en el país se encuentran alrededor de 54871 especies, siendo el primero a nivel mundial en aves y orquídeas; el segundo en plantas, anfibios, peces dulceacuícolas y mariposas; el tercero en reptiles y palmas; y el cuarto en diversidad de mamíferos. Colombia, como país megadiverso, tiene grandes responsabilidades en la conservación y uso sostenible de estos recursos, lo que deriva en retos cada vez mayores frente al avance acelerado de pérdida de biodiversidad. En este sentido, Colombia ha formado parte de varios Amuma y ha integrado múltiples acciones y programas para la atención del asunto ambiental desde diversas dimensiones.

Sin embargo, pese a lo dicho, Colombia todavía figura como el segundo país que más conflictos ambientales de gran escala tiene en el mundo, según el Atlas global de justicia ambiental, el cual registra aproximadamente 120 conflictos ambientales en el país. ${ }^{14}$ La minería y la extracción de petróleo, junto con los conflictos de destinación y uso de tierras representan los problemas ambientales más recurrentes en el país, aunque cobija también otros aspectos relacionados con el indebido manejo de residuos, la construcción de infraestructura y el manejo del uso hídrico. Sobra decir que la actividad petrolera es considerada una de las industrias que más impactos ambientales y en la biodiversidad genera a nivel local y global. En las distintas fases de la explotación petrolera y las prácticas operacionales típicas de la industria petrolera en zonas tropicales, se produce destrucción de la biodiversidad y del ambiente en general. No obstante, se trata

14 Los conflictos socioambientales se definen como las movilizaciones de las comunidades locales, movimientos sociales en contra de determinadas actividades económicas, la construcción de infraestructura o de eliminación de residuos/contaminación, por lo que los impactos ambientales son un elemento clave para la presentación de quejas y demandas. Tales conflictos suelen surgir de las desigualdades estructurales de ingresos y poder. El Atlas de justicia ambiental documenta los conflictos sociales relacionados con las reclamaciones contra impactos sociales o ambientales negativos percibidos con los siguientes criterios: 1) actividades económicas o legislaciones con resultados ambientales y sociales negativos reales o potenciales; 2) reclamo y movilización de organizaciones ambientales en contra de los daños que se hayan producido, o que sea probable que se produzcan, como resultado dicha actividad; 3) el registro del conflicto particular en uno o más medios de comunicación (Enviromental justice atlas, 2016). 
de uno de los principales productos exportados por Colombia, de allí que su ejercicio no tenga mayores restricciones jurídicas, ni a nivel nacional ni internacional, razón por la cual se han permitido el empleo de prácticas controversiales, como el fracking. ${ }^{15}$ En efecto, el Acuerdo de París y la Convención de Río dan cuenta de la debilidad o flexibilidad del derecho ambiental internacional en la formulación de disposiciones coercitivas en esta materia, de la mano de reglas internas que flexibilizan y priorizan las actividades de exploración y extracción de hidrocarburos en yacimientos convencionales y no convencionales.

$\mathrm{Al}$ respecto, los acuerdos comerciales asegurarán el desarrollo de las relaciones comerciales, y prestarán menor atención a la existencia de conflictos ambientales. En principio, los tratados de libre comercio hacen parte de un proceso de integración económica de países, que trasciende sobre la simple reducción de barreras arancelarias, de allí que acuerdos comerciales como los celebrados por Colombia con Estados Unidos, la Unión Europea, Canadá, México, Chile y otros, refuercen la implementación de distintas políticas públicas complementarias a lo comercial como medio/fin para su propio cumplimiento. Hoy por hoy, la mayoría de los tratados mencionados incluyen temas desde la eliminación de barreras al comercio, comercio electrónico, propiedad intelectual, contratación pública, medidas sanitarias, hasta asuntos laborales y ambientales, etc. Este complejo panorama obedece a una visión de desarrollo integral de los países, paralelo a la implementación de modelos de integración y gobernanza global.

Con todo, la respuesta jurídica de los acuerdos comerciales se sigue reduciendo a incentivar el comercio y algunos procesos de integración económica, procurando mayores garantías jurídicas en contraste con el medio ambiente, que ocupa un lugar secundario, limitándose a su fortalecimiento mediante la cooperación internacional no vinculante. En este sentido, el desarrollo sostenible será un objetivo de cada Estado individual, logrado por sus propios esfuerzos, contando así un débil apoyo o reforzamiento jurídico al plasmarse como principio jurídico, equilibrador del ejercicio de las actividades económicas reguladas. Según el principio de "sostenibilidad"

15 Práctica regulada mediante la Resolución 180742 de 2012, del Ministerio de Minas y Energía, por la cual se establecieron los procedimientos para la exploración y explotación de yacimientos no convencionales, incluido el fracking. Así mismo, el Decreto 3004 de 2013, por el que dicho ministerio ordenó expedir las normas técnicas y procedimientos en materia de fracking y yacimientos no convencionales, las cuales se publicaron en la Resolución 90341 de marzo de 2013 (Red por la Justicia Ambiental en Colombia, 2015). 
contenido en los acuerdos comerciales antes mencionados, los Estados no deberán, por un lado, tomar acciones que conduzcan a la disminución en los niveles de protección del medio ambiente; por el contrario, se pretenderá su promoción. ${ }^{16}$ Por otro, las medidas proteccionistas tampoco significarán un medio de discriminación arbitraria o injustificable entre los Estados, o una restricción encubierta al comercio o a la inversión. ${ }^{17}$

Empero, vale la pena advertir que la aplicación del mencionado principio no es un asunto del todo pacífico. La sostenibilidad en los términos descritos implica una fuerte tensión con la liberalización del comercio, pues los acuerdos señalados parecerían provocar la inaplicación de ley ambiental y la invalidez de medidas de protección al medio ambiente, en tanto pueden interpretarse como una barrera injustificable al comercio, y como un incumplimiento de los acuerdos comerciales.

En este sentido, importa mucho el papel que juega la libre apreciación ambiental de los Estados para la fijación de estándares de protección, teniendo en cuenta que por medio de estos se da lugar a argumentar tanto la aplicación de medidas irrisorias para la inobservancia de compromisos ambientales — con miras a afectar el comercio — como para la obstaculización del comercio internacional. En este último escenario, la violación del acuerdo comercial se determinará a partir de un juicio sobre la medida proteccionista impuesta, para evaluar si puede ser considerada como "arbitrariamente discriminativa" o "injustificable", o una "restricción encubierta al comercio internacional”. Sobre dicho aspecto, el órgano de apelación de

16 Téngase, sin exclusión de otros tratados, el criterio "sostenibilidad" como elemento rector de las relaciones comerciales en: Acuerdo Comercial Colombia-Estados Unidos, capítulo 18, objetivos y art. 18.9; Acuerdo sobre Medio Ambiente Colombia-Canadá (elemento anexo al Acuerdo Comercial Colombia-Canadá), capítulo 17, artículos 1071 y 1073, literal c; Acuerdo sobre Medio Ambiente Colombia-Unión Europea y Perú, título IX, artículos 267 y 271 . En tales disposiciones se expresa la armonización del desarrollo económico con la necesidad de proteger y conservar el medio ambiente y la biodiversidad, por lo que se afirma que "el comercio debería promover el desarrollo sostenible", o al menos, guardar "congruencia" con él. Sobra decir que dicho criterio —el de sostenibilidad_ opera en forma distinta, y con niveles de protección y orientaciones disímiles, aunque en algunos casos resulten similares.

17 Al respecto, ver los siguientes acuerdos comerciales: Colombia-Estados Unidos, capítulo 22 sobre "excepciones", art. 22.1; Acuerdo sobre Medio Ambiente ColombiaCanadá (elemento anexo al Acuerdo Comercial Colombia-Canadá), capítulo 17, artículos 1071 y 1073, literal c; Colombia-Unión Europea y Perú, título IX, artículo 267, numeral 5; Colombia-Salvador, Guatemala y Honduras, capítulo 12, artículo 12.9.3, literal c, etc. 
la OMC ha señalado que las bases del artículo XX del GATT — sobre mutatis mutandi incorporado en el TLC Colombia-Estados Unidos (art. 21.1) — ha justificado la "aplicación" de medidas proteccionistas con observación de su efecto más que de su contenido. Así las cosas, acorde a decisiones como el caso Estados Unidos c. Venezuela y Brasil: gasolina, se tiene por "discriminación injustificable" aquella que podía haberse "previsto" y que no fue "meramente voluntaria o inevitable"; 18 la arbitrariedad dependerá del grado de rigidez e inflexibilidad de la medida y si al imponerla no se tienen en cuenta las condiciones específicas de los países exportadores (caso Estados Unidos: camarones). ${ }^{19}$

18 "El 23 de enero de 1995, pocos días después de haberse constituido la OMC y entrado en funcionamiento su nuevo procedimiento de solución de diferencias, Venezuela presentó una reclamación ante el Órgano de Solución de Diferencias en la que sostenía que los Estados Unidos estaban aplicando unas normas que discriminaban a la gasolina importada. Venezuela solicitaba formalmente la celebración de consultas con los Estados Unidos, según establece el procedimiento de solución de diferencias de la OMC. El caso se debió a que los Estados Unidos aplicaban unas normas más exigentes a las características químicas de la gasolina importada que a las de la gasolina refinada en los Estados Unidos. Venezuela sostenía que era desleal que la gasolina estadounidense no tuviera que cumplir las mismas normas, infringiéndose así el principio de 'trato nacional' y que no podía justificarse tal acto alegando las excepciones a las normas generales de la OMC en favor de las medidas destinadas a proteger la salud y el medio ambiente. Casi exactamente un año después (el 29 de enero de 1996) el grupo especial completó su informe final. (Para entonces, Brasil se había sumado al caso, presentando su propia reclamación en abril de 1996. El mismo grupo especial consideró las dos reclamaciones). El grupo especial coincidió con Venezuela y Brasil, por lo que se constató que los Estados Unidos estaban infringiendo las normas de la OMC porque discriminaban a la gasolina importada". Cfr. OMC, Venezuela y Brasil contra los Estados Unidos: gasolina. Casos 2 y 4 de la OMC. Resolución adoptada el 20 de mayo de 1996.

19 A principios de 1997, la India, Malasia, Pakistán y Tailandia presentaron una reclamación conjunta contra la prohibición impuesta por Estados Unidos de importar determinados camarones y productos del camarón. El objetivo de la prohibición era proteger a las tortugas marinas. La Ley de Especies Amenazadas de 1973, de los Estados Unidos, enumeraba cinco especies de tortugas marinas amenazadas o en peligro que se encuentran en aguas estadounidenses y prohibía su "captura" en Estados Unidos, en sus aguas territoriales y en alta mar. De conformidad con dicha ley, se exigía que los arrastreros dedicados a la pesca del camarón utilizaran unos dispositivos para excluir a las tortugas (DET) en sus redes cuando pescaran en zonas donde había una probabilidad considerable de encontrar tortugas marinas. El artículo 609 de la Public Law 101-102, promulgada en 1989, estaba dedicado a las importaciones. Entre otras cosas, indicaba que no se podía importar a Estados Unidos camarón pescado con tecnologías que podían afectar mucho a determinadas tortugas marinas, a no ser que se certificara que la nación en cuestión contaba con un programa regulatorio y una tasa de capturas incidentales comparable a la de Estados Unidos, o que 
De cualquier forma, más allá de las dificultades, que en determinado caso se derivan de aplicar las directrices descritas y de los aportes señalados, las inclusiones normativas en los acuerdos comerciales citados en este texto suponen la toma de acciones ambientales por vía de proyectos y programas de recuperación ambiental. Como se dijo, bajo las orientaciones del desarrollo sostenible, desde los acuerdos comerciales se ha promovido la cooperación internacional entre países para la toma de medidas ambientales en puntos de interés común. No obstante, los mecanismos jurídicos para el monitoreo y control del comportamiento de los Estados partes resultan escasos tratándose de herramientas no vinculantes y composiciones normativas del soft law.

La inclusión de temas ambientales en los acuerdos comerciales se ha venido realizando en forma disímil con distintos aportes normativos, en muchos casos que expresan un contenido declarativo. Así, los tratados de Colombia-México, Colombia-Asociación Europea de Libre Comercio (EFTA, por su sigla en inglés), Colombia-Salvador, Guatemala y Honduras, y otros, que atienden al asunto ambiental sin ofrecer mayor profundidad; ${ }^{20}$

el entorno particular de la pesca en esa nación no representaba ninguna amenaza para las tortugas marinas. El órgano de Apelación en su informe dejó claro que, de conformidad con las normas de la OMC, los países tienen derecho a adoptar medidas comerciales para proteger el medio ambiente, y que las medidas para proteger a las tortugas marinas serían legítimas de conformidad con el artículo XX del Acuerdo General, siempre que se cumplan ciertos criterios como el de no discriminación. En efecto, Estados Unidos perdió el caso porque discriminaba a algunos miembros de la OMC, al haber ofrecido a los países del hemisferio occidental — principalmente del Caribe — asistencia técnica y financiera y unos períodos de transición más largos para que sus pescadores empezaran a utilizar los dispositivos para excluir a las tortugas. Por el contrario, no ofrecieron las mismas ventajas a los cuatro países asiáticos (la India, Malasia, Pakistán y Tailandia) que presentaron la reclamación (Venezuela y Brasil contra los Estados Unidos: gasolina. Caso 58 y 61 de la OMC. Resolución adoptada el 6 de noviembre de 1998).

20 Este hecho destaca en forma especial en los acuerdos celebrados por Colombia con Salvador, Guatemala y Honduras, donde las regulaciones contenidas en el acuerdo se limitan al reconocimiento de la potestad de los Estados para aplicar medidas proteccionistas, siempre que "no se apliquen de manera arbitraria o injustificada y a condición que esas medidas no constituyan una restricción encubierta al comercio o inversión internacional" (art. 12.9.3, literal c). Bajo la misma directriz, se incluye el Tratado de Colombia-México, donde se establece la facultad de cada Estado parte de fijar los niveles de protección por medio de la elaboración y aplicación de "medidas de normalización", y así, se declara el deber de los Estados parte de "trabajar de manera conjunta" para el fortalecimiento de los niveles de protección (arts. 14-07). El Tratado de Colombia-EFTA, cuyo alcance normativo se enfoca en la protección de la biodiversidad por medio del aseguramiento de los recursos 
apenas podría decirse que sobresalen en forma especial los acuerdos comerciales suscritos con Estados Unidos, la Unión Europea y Perú, y, en menor medida, Chile.

En el TLC de Colombia-Estados Unidos, se establece que cuando se presente una controversia derivada de una violación de la legislación ambiental que afecte el comercio o la inversión entre las partes, incluido alguno de los acuerdos multilaterales sobre el medio ambiente que ambas partes hayan puesto en vigor, se puede acudir al mecanismo general de solución de controversias del tratado. Esto hace que, en la práctica, opina García, sea más fácil acudir a los mecanismos comerciales, y así, sea más sencillo demandar el incumplimiento del TLC por la violación de una norma ambiental, frente a los mecanismos del tratado, que buscar la protección de alguno de los acuerdos multilaterales sobre el medio ambiente, cuando alguna actividad comercial ponga en riesgo el medio ambiente. Así mismo, cabe resaltar que estos tratados comerciales incluyen al medio ambiente solamente cuando se afecte el comercio de las partes, por lo que la óptica desde la cual se va a mirar la normatividad ambiental, va a estar supeditada por la comercial, lo que limita su alcance. En caso de presentarse este conflicto, las normas comerciales están más desarrolladas que las ambientales, sobre todo en cuanto a su exigibilidad. Igualmente, la protección ambiental en estos tratados comerciales se produce solo cuando exista una relación con el comercio y su resolución siempre estará matizada por la perspectiva comercial. En caso de conflicto, entonces, pareciera que hay una primacía inicial de lo comercial sobre lo ambiental (García Martínez, 2009, p. 157).

Observando el contenido del Acuerdo Comercial Colombia-Chile, sus mayores logros radican en que profundiza la construcción de relaciones para la cooperación internacional a fin de impulsar actividades ambientales consideradas de mutuo interés definidas por su artículo 18.3: a) Desarrollo forestal y recursos naturales; b) manejo de recursos hidrobiológicos; c) desertificación y recuperación de cobertura vegetal; d) mercados verdes; e) ecoturismo y turismo sostenible; f) biodiversidad; g) fortalecimiento institucional y normativo; h) control y monitoreo de la contaminación ambiental; i) política de manejo de la calidad del agua y tecnologías para su

genéticos, en cabeza de cada Estado parte, quien conforme a la legislación aplicable —nacional e internacional - establece las condiciones de acceso a este. Con todo, los anteriores se limitan al ejercicio del comercio bajo los presupuestos del 'desarrollo sostenible' y el reconocimiento de obligaciones ambientales fijadas en otros tratados, aun en los eventos donde estos no hagan referencia a cualquier Amuma. 
tratamiento; j) conservación de las áreas marinas y costeras; k) manejo de cuencas; 1) fortalecimiento de mecanismos para el fomento de la educación ambiental y la participación pública; m) pasivos ambientales; n) evaluaciones ambientales estratégicas; y o) otras que las partes puedan acordar.

La atención de dichas actividades se hace a través de la designación de coordinadores en el orden nacional: para Chile, la Comisión Nacional del Medio Ambiente; y para Colombia, el Ministerio de Ambiente, Vivienda y Desarrollo Territorial - Viceministerio de Ambiente. Se añade también la designación de puntos nacionales de contacto para la atención de consultas sobre las actividades de cooperación, y la recepción de informes periódicos por parte de los coordinadores. Estos puntos de contacto en Colombia corresponden igualmente al Ministerio de Ambiente, Vivienda y Desarrollo Territorial - Viceministerio de Ambiente; y en Chile, al Ministerio de Relaciones Exteriores.

Considerando las ausencias del Acuerdo Colombia-Chile sobre solución de controversias, los tratados de libre comercio celebrados con Estados Unidos, Canadá, la Unión Europea y Perú se encuentran un paso por delante — siendo un aspecto excluido del mecanismo dispuesto para eventos de incumplimiento del tratado (art. 16.2.3)—, participación pública y otros aspectos institucionales. Así, aunque los demás tratados mencionados fomentan también actividades de cooperación, el convenido con Chile dispone de mecanismos más complejos para la verificación de implementación de sus respectivos acuerdos en materia ambiental y sus efectos, en los cuales se comprende también el seguimiento a las legislaciones y políticas internas.

Sobra decir que los tratados suscritos con Canadá, Estados Unidos, la Unión Europea y Perú, y también Chile, en principio, están orientados al respeto de la soberanía de los Estados de establecer sus propias políticas ambientales, por lo que es discrecional la fijación de los niveles internos que se consideren adecuados para proteger el medio ambiente. Así las cosas, son los mismos Estados los responsables de la protección de los recursos naturales acorde a los mecanismos de protección interna. Los capítulos de los tratados relacionados con el tema ambiental se limitan a observar que los países cumplan su propia legislación ambiental, reflejando "altos estándares ambientales internacionales" y sin promover indebidamente el comercio, ya sea obstaculizándolo o bien disminuyendo o inaplicando 
medidas proteccionistas en aras de generar incentivos para el comercio o la inversión. ${ }^{21}$

Por otra parte, superando el paragón entre los tratados celebrados, en los acuerdos Colombia-Canadá, Colombia-Estados Unidos y ColombiaUnión Europea-Perú, se asume el cumplimiento de varios compromisos a cargo de cada Estado. Específicamente, las partes se obligan a "asegurar" el derecho a presentar denuncias por infracciones a la legislación ambiental interna, así como contar con mecanismos judiciales y administrativos para la sanción de estas, y los procesos de reparación ambiental. Tales mecanismos deben cubrir tanto la acción en contra de personas — naturales y jurídicas - como en contra de las autoridades, en los eventos que se abstengan de adoptar medidas adecuadas para la aplicación de la legislación ambiental interna. ${ }^{22}$ De la misma manera, será deber de las partes impulsar el establecimiento de mecanismos flexibles, voluntarios y basados en incentivos, que puedan contribuir a la protección ambiental; ${ }^{23}$ promover

21 Así, respecto a Chile, el artículo 18.2 (2): “Cada parte se asegurará que sus políticas y leyes promuevan y establezcan altos niveles de protección ambiental y de conservación y uso sostenible de los recursos naturales; y se esforzará por seguir mejorando sus niveles de protección en estas materia". En cuanto a Canadá, el artículo $2^{\circ}$ del respectivo Acuerdo sobre Medio Ambiente: "Reconociendo el derecho soberano de cada una de las partes de establecer sus propios niveles de protección ambiental nacional y sus políticas y prioridades de desarrollo ambiental, al igual que de adoptar o modificar consiguientemente sus leyes y políticas ambientales, cada parte se asegurará de que sus leyes y políticas ambientales establezcan altos niveles de protección ambiental y se esforzará por seguir desarrollando y mejorando esas leyes y políticas". En el mismo sentido, el acuerdo suscrito con Estados Unidos, artículo 18.1: “[...] cada parte se asegurará de que sus leyes y políticas proporcionen y estimulen altos niveles de protección ambiental y se esforzará por seguir mejorando sus respectivos niveles de protección ambiental". Y, finalmente, en cuanto a la Unión Europea y Perú, el artículo 268 de su respectivo acuerdo: “[...] cada parte procurará asegurar que sus leyes y políticas pertinentes contemplen e incentiven altos niveles de protección ambiental y laboral".

22 Ver, respectivamente: Acuerdo Comercial Colombia-Estados Unidos, capítulo 18, artículo 18.3; Acuerdo sobre Medio Ambiente Colombia-Canadá, artículo $3^{\circ}$, sobre "Disponibilidad de procedimientos y normas procesales". Contrario a los anteriores, el acuerdo suscrito con Unión Europea y Perú, que no hace mención expresa de lo descrito.

23 Acuerdo Comercial Colombia-Estados Unidos, capítulo 18, artículo 18.4; Acuerdo Comercial Colombia-Unión Europea y Perú, capítulo IX, artículo 271.4. Sobre el asunto, el Acuerdo sobre Medio Ambiente Colombia-Canadá no establece disposición alguna al respecto. 
la participación de la sociedad civil por medio de distintos mecanismos; ${ }^{24}$ fortalecer y ampliar la capacidad de las instituciones nacionales responsables de la conservación y uso sostenible de la diversidad biológica; ${ }^{25}$ y fomentar conciencia pública de la legislación ambiental; ${ }^{26}$ entre otros.

El cumplimiento de dichos compromisos en gran medida dependerá de la voluntad interna de cada Estado parte. Para ello, se han diseñado precisamente dentro de los acuerdos señalados mecanismos para el seguimiento interno del tratado, creando distintos entes para la administración de sus respectivos acuerdos. Así, el Tratado Colombia-Canadá cuenta con el Comité del Medio Ambiente para tal efecto; Colombia-Unión Europea y Perú, con el Comité de Comercio integrado por el Subcomité de Comercio y Desarrollo Sostenible; y el Acuerdo Colombia-Estados Unidos se vale de una estructura más compleja integrada por secretarías para asuntos ambientales, encargadas de la recepción de denuncias públicas sobre inaplicación efectiva de la legislación ambiental; una Comisión de Cooperación Ambiental creada por el ACA Colombia-Estados Unidos para la formulación de recomendaciones, conjuntamente con otros comités consultivos y consultores nacionales; y un Consejo para Asuntos Ambientales para la consideración y discusión sobre la implementación del acuerdo en materia ambiental.

Empero, todos los comités e instituciones anteriores operan bajo los límites impuestos sobre el respeto a la soberanía. En tal sentido, ninguna de las anteriores funge como organismo para el control y aseguramiento del tratado en sus aspectos ambientales. Estos operan como supervisores y sus funciones principales estarán asociadas con el fortalecimiento de relaciones de cooperación internacional y con la construcción de acciones complementarias para la mejoría del medio ambiente, en principio, desde el soft law. En contraste con los asuntos comerciales, los alcances de controles y seguimientos sobre el cumplimiento de los acuerdos en materia ambiental son muy limitados y débiles normativamente.

24 Cfr. Acuerdo Comercial Colombia-Estados Unidos, capítulo 18, artículo 18.6; Acuerdo Comercial Colombia-Unión Europea y Perú, capítulo IX, artículos 280.7 y 282; y Acuerdo sobre Medio Ambiente, artículo $4^{\circ}$.

25 Aspecto mencionado en el Acuerdo Comercial Colombia-Unión Europea y Perú, capítulo IX, artículo 272.6; y el Acuerdo sobre Medio Ambiente en su artículo $8^{\circ}$ como actividad prioritaria de cooperación.

26 Aspecto únicamente mencionado en el Acuerdo Comercial Colombia-Estados Unidos, capítulo 18, artículo 18.6.1. 
Considerando el respeto de la soberanía y la libre apreciación de los Estados sobre sus propias configuraciones normativas ambientales, los seguimientos efectuados respecto al cumplimiento del tratado en materia ambiental se logran por medio de la emisión de recomendaciones no vinculantes. Por otro lado, los asuntos asociados al tema ambiental -o a la garantía de derechos laborales - se encuentran en esencia sustraídos del mecanismo de solución de controversias interno de los TLC ColombiaEstados Unidos y Colombia-Unión Europea y Perú. De esta manera, estos parecieran estar excluidos de cualquier declaratoria de responsabilidad y/o compensación monetaria, a no ser que la discusión se circunscriba a la utilización de medidas proteccionistas como obstáculo injustificado al comercio internacional en los términos ya antes mencionados; o bien, se detecte la inaplicación recurrente de las legislaciones que puedan tener efectos sobre el comercio. ${ }^{27}$

En forma similar, el AMA Colombia-Canadá no cuenta con igual mecanismo interno para la solución de controversias en asuntos comerciales. Acorde con el artículo 2102 del Acuerdo Comercial Colombia-Canadá, los asuntos ambientales se encuentran también excluidos del mecanismo interno de solución de conflictos. También, se prohíbe en el mismo AMA de Colombia-Canadá demandar en la legislación interna a otra parte por incumplimiento de este último acuerdo, por lo que únicamente se habilita la presentación escrita de solicitud de "consultas" ante los coordinadores nacionales que la otra parte haya designado, en los casos que se crea que pueda afectarse la implementación o interpretación del AMA. El propósito de dichas consultas será la búsqueda de un mutuo acuerdo sobre el asunto; en caso de no resolverse, el asunto remitirá nuevamente a consulta ante la autoridad designada por las partes. $^{28}$

27 En principio, los acuerdos comerciales aquí estudiados, Colombia-Canadá y ColombiaUnión Europea-Perú, no contemplan en forma expresa las excepciones del artículo XX del GATT sobre mutatis mutandi incorporadas en el TLC Colombia-Estados Unidos y Colombia-Chile (art. 3.4); y/o el artículo 18.11.7 del TLC con Estados Unidos sobre "Consultas ambientales". Con todo, se considera que lo dicho no es óbice para que, en los eventos descritos, se pueda argumentar el incumplimiento de cualquiera de los acuerdos haciendo una interpretación sistemática de su respectivo contenido.

28 Establece el artículo 2102 del acuerdo citado "Ámbito y cobertura": "1. Salvo por cualquier asunto que surja de conformidad con los capítulos dieciséis (Asuntos laborales) y diecisiete (Asuntos ambientales) o salvo cualquier disposición en contrario en este acuerdo, el procedimiento de este capítulo se aplicará respecto a la solución de todas las controversias entre las partes relativas a la aplicación o interpretación de este acuerdo, o 
Otras de las debilidades en que vale la pena hacer hincapié es en la capacidad de los mecanismos diseñados para hacer seguimiento de los acuerdos comerciales en materia ambiental. Como se dijo, los procesos de monitoreo se crearon bajo parámetros normativos del soft law; sin embargo, fuera del debate de la naturaleza normativa, persisten otras debilidades de diseño que permiten cuestionar la efectividad del acuerdo en materia ambiental. En efecto, las reuniones de seguimiento, monitoreo y recomendaciones se realizan con intervalos de largos períodos de tiempo, usualmente anual, y dada la amplitud y complejidad de los temas abordados, no podrían verificarse importantes avances en la materia.

Por otro lado, herramientas importantes para el monitoreo de los acuerdos, como los sistemas de denuncia pública que cuentan los tratados Colombia-Estados Unidos y Colombia-Unión Europea y Perú, aún no operan plenamente ni ofrecen información accesible. Así las cosas, en lo relacionado al Tratado Colombia-Unión Europea y Perú, a la fecha no se reporta la presentación de denuncia alguna relativa a la inaplicación de la legislación ambiental, no pudiendo todavía determinarse con certeza la eficacia del sistema. De igual forma, el Acuerdo Comercial ColombiaEstados Unidos no muestra registro de cartas o entendimientos sobre la designación de la Secretaría para Asuntos Ambientales y la recepción de denuncias ambientales. ${ }^{29}$ Entre tanto, el TLC suscrito con Estados Unidos habilita en su artículo 18.7 la presentación de denuncias ante la Secretaría

cuando una parte considere que: a) una medida vigente o en proyecto de la otra parte es o pudiera ser incompatible con las obligaciones de este acuerdo; b) la otra parte ha incumplido de alguna manera las obligaciones de este acuerdo; y c) un beneficio que la parte pudiera razonablemente haber esperado recibir en virtud de alguna disposición de los siguientes capítulos: (i) capítulo dos (Trato nacional y acceso a mercados de mercancías), tres (Reglas de origen), cuatro (Procedimientos de origen y facilitación del comercio), siete (Medidas de emergencia y defensa comercial) o catorce (Contratación pública), o (ii) capítulo nueve (Comercio transfronterizo de servicios), esté siendo anulado o menoscabado como resultado de la aplicación de una medida de la otra parte que no es incompatible con este acuerdo. 2. En toda controversia en relación con el párrafo 1(c), un panel establecido de conformidad con este capítulo tomará en consideración la jurisprudencia relativa a la interpretación del artículo XXIII:1(b) del GATT 1994 y el artículo XXIII(3) del AGCS. Una parte no podrá invocar el párrafo 1 (c)(i), en relación con ninguna medida sujeta a una excepción en virtud del artículo 2201 (Excepciones - Excepciones generales) ni invocar el párrafo 1(c), en relación con ninguna medida sujeta a la excepción en virtud del artículo 2205 (Excepciones - Industrias culturales)".

29 Así, nótese lo dicho en la base de publicación de tratados del Ministerio de Comercio, Industria y Turismo, en http://goo.gl/GqODYl, consulta del 20 de mayo de 2016. Lo 
de la Comisión de Cooperación Ambiental del North American Agreement on Environmental Cooperation (NAAEC) por personas de una parte distinta a Estados Unidos, en los eventos en que considere que este último está dejando de observar efectivamente su legislación ambiental. Por su parte, en Colombia, apenas a finales del año 2015, luego de tres años de vigencia del tratado, se hizo apertura a convocatoria de ONG para ubicar la Secretaría para Asuntos Ambientales en sus instalaciones. ${ }^{30}$ Dicho lo anterior, aunque el sistema de denuncias públicas descrito es operante para el caso de Estados Unidos por intermedio de la NAAEC, se desconoce el hecho de que se hayan presentado quejas por motivo del TLC ColombiaEstados Unidos, del mismo modo que se desconoce si Colombia ha sufrido denuncias por tales hechos.

Así las cosas, la mayor operatividad de los acuerdos comerciales se concentra, como se anticipó, en las actividades de cooperación internacional para la ejecución de acciones y programas para el mejoramiento de las condiciones ambientales, y la promoción de prácticas sostenibles. Ahora bien, este tipo de acuerdos de cooperación no son un elemento novedoso de los acuerdos comerciales; por el contrario, han sido preexistentes a la celebración de estos. En cualquier caso, tales acuerdos sirven de instrumento para focalizar recursos, útiles para el mejoramiento de la gestión y conservación del medio ambiente y las condiciones de vida en general. No obstante, estos acuerdos han estado limitados por las dificultades operativas que cada escenario pueda suscitar. En el caso colombiano, por ejemplo, se ha evidenciado que las transiciones burocráticas al momento de ejecutar políticas ambientales a nivel sectorial provocan la inestabilidad de la agenda de protección al medio ambiente, invocando incluso diversas interpretaciones del concepto 'desarrollo sostenible', ya sea porque contemplan prioridades individuales o porque incorporan nuevos asuntos que suelen actuar en perjuicio del medio ambiente. La Contraloría General de la República afirma que en Colombia también son recurrentes las debilidades asociadas a la debilidad institucional y a la desarticulación de las autoridades para la gestión ambiental (2011).

dicho, igualmente, en la base de publicaciones de la Organización de los Estados Americanos (OEA), en http://goo.gl/YkrI5O, consulta del 20 de mayo de 2016.

30 Sobre este punto, se puede consultar la siguiente página web: Ministerio de Comercio, Industria y Turismo, Se abre convocatoria para ubicar la Secretaría de Asuntos Ambientales en el marco del TLC con Estados Unidos, en http://www.tlc.gov.co/publicaciones.php?id=35322, consulta del 20 de junio de 2016. 
Las circunstancias antes mencionadas bien podrían poner en entredicho la eficacia de la mayoría de acciones derivadas de los acuerdos. Con todo, el análisis en términos de efectividad de los programas derivados de los citados tratados corresponde a un estudio distinto al aquí expuesto. En tal caso, valdría la pena la observación de las complicaciones que trae en sí mismo la aplicación de modelos fundados en la expresión "desarrollo sostenible" y sus consecuencias derivadas en los acuerdos comerciales. ${ }^{31}$

De cualquier modo, sin aminorar la importancia del fortalecimiento de las relaciones de cooperación, la reflexión sobre los acuerdos comerciales como respuesta a los conflictos ambientales a primeras podría decirse que se muestra débil e insuficiente. Siempre que no haya afectación o incumplimiento de los acuerdos comerciales en materia comercial, el tema medioambiental queda en último plano, considerando la inexistencia de medios para vincular los Estados, los déficits en la implementación de los medios de monitoreo, las debilidades en términos de diseño y las compli-

31 Es claro que el crecimiento económico desmedido en los países no necesariamente es equivalente con el concepto de desarrollo, toda vez que este último necesariamente debe considerarse de la mano de criterios de bienestar y sostenibilidad. Así, comprendiendo el 'desarrollo sostenible', sin mayor atención a los debates de fondo, como el equilibrio en las dimensiones económicas, sociales y ambientales, la aplicación de tal concepto en la práctica ha conducido en varios eventos al sacrificio de alguna de sus dimensiones. Hoy por hoy, existen casos donde incluso la implementación de políticas ambientales termina privilegiando la sostenibilidad ecológica a costa de la sostenibilidad social, generando algunas incertidumbres sobre la factibilidad del concepto. Al respecto, explica Guillermo Foladori, lo anterior se debe a la polarización de riquezas y los altos niveles de pobreza y exclusión social donde se circunscribe la implementación de políticas ambientales. Foladori cita entre varios ejemplos el caso de la agricultura convencional y la agroecología, en donde la primera es criticada por sus consecuencias nocivas sobre el medio ambiente (degrada el suelo con químicos y sobrerroturación, impacta la salud humana por el uso de tóxicos y antibióticos, genera pérdida de biodiversidad al promover el monocultivo extensivo, contamina los cursos de agua, etc.), y la segunda surge como propuesta del movimiento ambientalista para reducir casi todos aquellos impactos negativos, empero, guardando afectaciones negativas sobre la sociedad. Por una parte, el 'mundo' comerá mejor, sin agrotóxicos, la naturaleza se reproducirá y será legada en mejores condiciones para las futuras generaciones. Por otro, el proceso de concentración de las unidades de producción agroecológicas conducirá a la pobreza de muchos y el crecimiento económico, concentración del suelo y del capital de pocos. Los productores agroecológicos deberán vender su producción al mercado, donde, nuevamente, aparecerá la concentración de la compra en manos de grandes transnacionales; los propios productores agroecológicos entrarán en competencia entre ellos, con lo cual unos pocos se enriquecerán y muchos se empobrecerán (2006, p. 15). 
caciones internas de los Estados para hacer efectivo el logro de objetivos plasmados en la ley ambiental, o incluso en los tratados de libre comercio. Sobra decir a este punto que buena parte del cumplimiento de los acuerdos comerciales en materia ambiental remite a las fortalezas internas de cada Estado, lo que conduce a que se circunscriban al escenario de ineficacia de normas ambientales ya antes esbozado.

\section{Conclusión}

Con base en todo lo descrito, se puede concluir que buena parte de las composiciones normativas relacionadas con la protección al medio ambiente corresponden a estructuras del soft law. Dicha categoría advierte una debilidad normativa al existir lo que podría decirse un déficit del hard law en los acuerdos de libre comercio, pese a la trascendencia y relevancia del tema ambiental. El ordenamiento jurídico internacional en materia ambiental ha sido construido distante a la gestión interna, y expone niveles de debilidad para la consecución de los objetivos normativos prescritos. En este sentido, la menor incidencia y capacidad normativa de las regulaciones ambientales ha terminado perpetuando y convalidando los modelos de desarrollo existentes.

En últimas, las dificultades asociadas a la determinación de ¿qué es lo sostenible? faculta también la creación de proposiciones normativas débiles y la implementación de acciones de relativa ambigüedad, de manera que hasta cierto punto se justifica la no modificación de los modelos de gestión, en parte también promovida por el principio de respeto a la soberanía y la libre apreciación ambiental de los Estados. No obstante, en contraste con los intereses comerciales, el medio ambiente resulta ser un asunto de menor prioridad jurídica, por lo que su medio de protección atenderá a vías políticas no vinculantes mediante la ejecución de proyectos y programas de intervención ambiental, quizá de dudosa eficacia si se considera la posible permanencia de causas de degradación ambiental asociadas a los modelos de gestión económica. En todo caso, el déficit de hard law en las estructuras normativas vinculadas al medio ambiente muestra la priorización jurídica de lo comercial sobre lo ambiental, que, como se ha sostenido, continúa ocupando un segundo plano en la agenda de los Estados. 


\section{Referencias}

\section{Textos y libros}

Abbott, K. \& Snidal, D., "Hard and soft law in international governance", International Organization, 2000, 54, pp. 421-457.

Alarcón, G., "El soft law y nuestro sistema de fuentes", en Arrieta y Martínez de Pisón, J., Collado Yurrita, M. A. \& Zornoza Pérez, J. J. (dirs.), Tratado sobre la Ley General Tributaria: homenaje a Álvaro Rodriguez. Bereijo, 2010.

Ángeles, B., "Soft law: ¿mucho ruido y pocas nueces?", Revista Electrónica de Estudios Internacionales (REEI), 2004, (8), pp. 1-40.

Barani, L., "Hard and soft law in the European Union: the case of social policy and the open method of coordination", en Constitutionalism \& governance beyond the State. $N^{\circ}$ 2, Universite Libre de Bruxelles, 2006.

Beltrán M., García, F., Borges J. \& Ortega, A., "Apertura comercial y medio ambiente”, Interciencia, 2002, 27, (5), pp. 259-263.

Brañes, R., La fundación del derecho ambiental en América Latina, Fondo de Cultura Económica, 2004.

Bravo, E., "Los impactos de la explotación petrolera en ecosistemas tropicales y la biodiversidad", Ed. Acción Ecológica, 2007.

Cerdá T., Emilio, "Comercio internacional y medio ambiente", Economía y Medio Ambiente, ICE: Información Comercial Española, 2009, (847), pp. 119-120.

Chicharro, A., "El carácter de soft law de los instrumentos internacionales sobre desarrollo sostenible", en Domínguez Martín, Rafael \& Tezanos Vázquez, Sergio (eds.), Desafíos de los estudios del desarrollo: actas del I Congreso Internacional de Estudios del Desarrollo, Universidad Pública de Navarra, 2013.

Chichilnisky, G., "North-South Trade and the Global Environment", American Economic Review, 1994, 84, pp. 851-874.

Chinkin, C., "Normative development in the international legal system", en Shelton, D. (ed.), Commitment and compliance. The role of non-binding norms in the international legal system, Oxford University Press, Oxford, 2000, pp. 21-42.

Colmegna, P., "Impacto de las normas de soft law en el desarrollo del derecho internacional de los derechos humanos", Revista Electrónica del Instituto de Investigaciones Ambrosio L. Gioja, 2012, VI, (8). 
D’Amato, A. \& Engel, K., International environmental law anthology, Andersen Publishing Company, 1996.

Del Toro Huerta, M., "El fenómeno del soft law y las nuevas perspectivas del derecho internacional", Anuario Mexicano de Derecho Internacional, 2006, VI.

Foladori, G., "La insostenibilidad social del desarrollo sostenible", Portularia: Revista de Trabajo Social, 2006, VI, (2).

García Martínez, M., "Relaciones entre el tratado de libre comercio con Estados Unidos de América y los acuerdos multilaterales ambientales", International Law, Revista Colombiana de Derecho Internacional, 2009, (14), pp. 133-161.

García, H., "Eficacia, efectividad y eficiencia de las normas que regulan el ejercicio del derecho de huelga y su método de composición. Apuntes críticos". Rev. DT, 2006.

Gómez, M. F., Moreno, L. A., Andrade, G. I. \& Rueda, C. (eds.), Biodiversidad 2015: Estado y tendencias de la biodiversidad continental de Colombia, Instituto de Investigación de Recursos Biológicos Alexander von Humboldt, Bogotá, 2016.

Jankilevich, S., Las cumbres mundiales sobre el ambiente: Estocolmo, Rio y Johannesburgo, 30 años de historia ambiental, Documento de Trabajo $\mathrm{N}^{\circ} 106$, Universidad de Belgrano, 2003.

Larach, M. A., Comercio y medio ambiente en la Organización Mundial del Comercio, Naciones Unidas-Cepal-División de Comercio Internacional, Transporte y Financiamiento, 1998.

López, M., Crisis climática: el legado 20 años después de la 'Cumbre para la Tierra', Convención Marco de las Naciones Unidas sobre el Cambio Climático, Balance de resultados COP 18-MOP 81, 2012.

Mance, H., "La política de la sostenibilidad: ascenso y declive del Ministerio del Medio Ambiente colombiano", en Gobernabilidad, instituciones y medio ambiente en Colombia, Foro Nacional Ambiental, 2008.

Nava, C., "El Acuerdo de París. Predominio del soft law en el régimen climático", Boletín Mexicano de Derecho Comparado, 2016, 147.

Rodríguez, M., Crisis ambiental y relaciones internacionales: hacia una estrategia colombiana, Fescol-Fundación Alejandro Ángel Escobar- Cerec, 1994.

Rojas, S. \& Lloreda, P. M., Las reglas de juego del TLC: aspectos legales del tratado con Estados Unidos, Edit. Planeta Colombiana S.A., Bogotá, D.C., 2013.

Sánchez, G., "Desarrollo y medio ambiente: una mirada a Colombia", Revista Economía y Desarrollo, 2002, (1). 
Shaffer, G. \& Pollack, M., "Hard vs. soft law: alternatives, complements, and antagonists in international governance", Minnesota Law Review, 2010, 94, pp. 706-799.

Valencia, H., Derecho internacional público, $1^{\mathrm{a}}$ ed., Editorial Universidad Pontificia Bolivariana, Bogotá D.C., 2003.

\section{Referencias electrónicas}

“¿What does Colombia export?”, en Enviromental justice atlas, en http:// goo.gl/mRBMv6, consulta del 13 de julio de 2016.

“¿What is the project about?”, en Enviromentaljustice atlas, en https:/ / ejatlas. org/about, consulta del 13 de julio de 2016.

"Colombia", en Enviromental justice atlas, en https:/ / ejatlas.org/country/ colombia, consulta del 13 de julio de 2016.

Compliance Committee, Note by the secretariat of United Nations Kyoto's Protocol. CC/EB/25/2014/2, 20 August 2014: “Canada's withdrawal from the Kyoto Protocol and its effects on Canada's reporting obligations under the Protocol", en https://goo.gl/iBL4tr, consulta del 3 de junio de 2016.

Contraloría General de la República, "Estado de los recursos naturales y del ambiente 2010-2011: evaluación de la implementación de la política nacional de humedales interiores en Colombia", 2011, en http://goo.gl/c7Xyc2, consulta del 13 de mayo de 2016.

European Union, EU trade relations with Latin America: results and challenges in implementing the EU-Colombia/Perú Trade Agreement, 2016, p. 37, en http://goo.gl/xCX1WX, consulta del 20 de junio de 2016.

Ministerio de Ambiente, Vivienda y Desarrollo Territorial (MAVDT), Tratados y convenios internacionales - gestión ambiental sectorial, 2011, en https:// goo.gl/kx8Bhn, consulta del 3 de abril de 2016.

Ministerio de Comercio, Industria y Turismo, Acuerdos vigentes, en http:/ / goo.gl/GqODYl, consulta del 20 de mayo de 2016.

Ministerio de Comercio, Industria y Turismo, Se abre convocatoria para ubicar la Secretaría de Asuntos Ambientales en el marco del TLC con Estados Unidos, en http://www.tlc.gov.co/publicaciones.php?id=35322, consulta del 20 de junio de 2016.

Naciones Unidas, Informe sobre la disparidad en las emisiones, 2012, en http:/ / goo.gl/cigYu7, consulta del 3 de junio de 2016.

Naciones Unidas, La ONU y el cambio climático, 2016, en http://goo.gl/ xUUbaV, consulta del 3 de junio de 2016. 
Naciones Unidas, Los mecanismos de Kyoto, 2016a, en http://goo.gl/DSc6BS, consulta del 9 de agosto de 2016.

Naciones Unidas, Status of ratification of the Kyoto Protocol, note (2), 2016b, en http://goo.gl/IHRSXI, consulta del 3 de junio de 2016.

Naciones Unidas, Un poco de bistoria - De la ratificación al cumplimiento, 2016c, en http://goo.gl/fxij3g, consulta del 3 de junio de 2016.

OMC, Primeros años: inicio del debate sobre el medio ambiente en el GATT y la OMC, en http://bit.ly/2z23dt3, consulta del 20 de octubre de 2017.

OMC, Resolución adoptada el 20 de mayo de 1996, en https:/ /goo.gl/QHrFmp, consulta del 12 de agosto de 2016.

OMC, Venezuelay Brasil contra los Estados Unidos: gasolina. Casos 2 y 4 de la OMC. Resolución adoptada el 20 de mayo de 1996, en https://goo.gl/QHrFmp, consulta del 12 de agosto de 2016.

OMC, Venezuela y Brasil contra los Estados Unidos: gasolina. Caso 58 (y 61) de la OMC. Resolución adoptada el 6 de noviembre de 1998, en https://goo.gl/ QHrFmp, consulta del 12 de agosto de 2016.

Organización de los Estados Americanos (OEA), en http://goo.gl/YkrI5O, consulta del 20 de mayo de 2016.

Red por la Justicia Ambiental en Colombia (RJAC), ¿En qué va el fracking en Colombia y el mundo?, 2015, en https://goo.gl/eKHcse, consulta del 19 de julio de 2016.

Rey, O., El derecho ambiental como garante de la justicia social, 2008, p. 15, en https://goo.gl/14uztQ, consulta del 4 de junio de 2016.

World Commission on Environment and Development, United Nations, Report of the World Commission on Environment and Development: our common future, 1987, p. 41, en http://goo.gl/2SXmzI, consulta del 12 de junio de 2016.

World Wide Fund for Nature, Protocolo de Kioto: situación actual y perspectivas, 2016, en http://goo.gl/w6zp1n, consulta del 9 de agosto de 2016. 